\title{
ASSÉDIO MORAL NAS RELAÇÕES DO TRABALHO
}

\section{MORAL ASSASSION IN WORK RELATIONS}

\section{GABRIELA SCHELLENBERG PEDRO BOM KALED}

Mestranda em Direito Empresarial e Cidadania no Centro Universitário Curitiba UNICURITIBA.

\section{RESUMO}

O presente estudo tem por objeto a análise dos conceitos de assédio moral no ambiente de trabalho, bem como suas consequências tanto para a saúde do trabalhador, como para a organização de uma maneira geral e para o empregado assediador. Ainda, serão abordadas as possibilidades de comprovação do assédio moral na esfera judicial, bem como os métodos de prevenção e reparação de danos sofridos.

PALAVRAS-CHAVE: Assédio Moral no Trabalho, Dano Moral, Prova, Reparação, Prevenção.

\section{ABSTRACT}

The aim of the present essay is to analise the concepts of psychological harassment in a workplace as well as the consequences for the workers's health, the whole organization and the harasser worker. Even though, it will be approached the possibilities of the psychological harassment's confirmation in the judicial sphere as the prevention and repair of the suffered damages

KEYWORDS: Psychological Harassment in a Workplace; Moral Damage; Proof; Repair; Prevention. 


\section{Personalidade Acadêmica Homenageada:}

Carlos Aurélio Mota de Souza (Universidade Ibirapuera - UNIB)

\section{INTRODUÇÃO}

O presente estudo tem por objeto a análise do assédio moral nas relações do trabalho, apontando seus conceitos, características, bem como a possibilidade de sua comprovação na via judicial, além de verificar as possibilidades de prevenção do fenômeno e da devida reparação por meio da tutela jurisdicional. A metodologia apresentada é a dedutiva com base em análises bibliográficas, nas principais leis, jurisprudências, doutrinas bem como artigos científicos relacionados ao tema.

O estudo do assédio moral nas relações de trabalho é de suma importância para o mundo jurídico e para a sociedade no geral, devido às graves consequências tanto psíquicas quanto físicas geradas na saúde do trabalhador ofendido, além da sua notória perda de autoestima proveniente das atitudes perpetradas pelos assediadores.

GOMES (2005, p. 112) lembra que num mundo dominado pela ideologia neoliberal, a competitividade cria ou incita conflitos econômicos entre nações, exige alterações drásticas nas linhas de produção das empresas, de forma a levar em conta a produtividade e valorizar a qualidade, com visíveis redirecionamentos à política de pessoal. Contudo, verifica-se com frequência que empresas para aumentarem sua competitividade no mercado e manterem a própria sobrevivência, buscam o aumento desenfreado na produtividade com maior eficiência, obtendo, assim, o aumento da produtividade com maior eficiência, ou seja, menos custos e maior flexibilização da produção.

Como é inquestionável que a ocorrência do assédio moral ofende frontalmente o princípio da dignidade da pessoa da pessoa humana, princípio este insculpido no artigo $5^{\circ}$ da CRFB, foi um grande avanço a nova Lei 13.467 de 13.07.2017, que trouxe em seu bojo a proteção à violação aos danos extrapatrimoniais, dentre eles o dano moral decorrente do assédio moral no trabalho.

Na prática do fenômeno, o agressor se utiliza de atitudes perversas com o objetivo de humilhar e desestabilizar a vítima, fazendo com que esta fique acuada e, muitas vezes, peça demissão para se livrar da situação constrangedora. Na verdade, a vítima sente-se culpada pela situação e acredita que está fazendo algo errado, enquanto na realidade, está sendo mais uma vítima do sistema perverso. 


\section{Personalidade Acadêmica Homenageada:}

\section{Carlos Aurélio Mota de Souza (Universidade Ibirapuera - UNIB)}

Se não perder o emprego, ou por iniciativa própria ou do empregador, o trabalhador assediado poderá ainda sofrer ansiedade, depressão, sentimentos de inutilidade, além da tentativa de suicídio, por sentir que não consegue mais desenvolver seu trabalho, que deveria ser fonte de dignidade e meio de sustento à família.

Considerando as consequências do assédio no ambiente do trabalho e não apenas à saúde do trabalhador, é que se faz necessário um estudo a fim de conhecer o tema de maneira geral, verificando suas consequências jurídicas e também meios de prevenção e reparação, caso ele ocorra.

Infelizmente o assédio moral não possui tipificação no Código Penal apesar de sua gravidade, necessitando de uma atenção particular por parte dos legisladores.

Além disso, as informações adequadas com relação ao tema, levam a uma correta verificação por parte dos trabalhadores e operadores do direito, com o fito de evitar a banalização do instituto do dano moral, eis que tais questões só devem ser arguidas se de fato foram constatadas a existência dos requisitos ensejadores de tal situação.

\section{ASSÉdIO MORAL NO AMBIENTE DE TRABALHO}

\subsection{ASPECTOS GERAIS E CONCEITO}

Como se sabe, o assédio moral pode ocorrer nas escolas e no ambiente familiar e não apenas no trabalho.

Contudo, este estudo analisará o fenômeno apenas no âmbito trabalhista, embora nos demais locais sua presença seja tão prejudicial quanto no mundo trabalho.

No ambiente laboral o assédio moral significa todos os atos comissivos ou omissivos, atitudes, gestos ou comportamentos do empregador ou de seus prepostos, que traduzem uma atitude de contínua ou ostensiva perseguição, com intuito de causar danos relevantes às condições físicas, psíquicas, morais e até existenciais do ofendido. (GUEDES, 2008, p. 39) 


\section{Personalidade Acadêmica Homenageada:}

\section{Carlos Aurélio Mota de Souza (Universidade Ibirapuera - UNIB)}

Já Delgado (2018, p. 765), define o assédio moral como sendo a conduta reiterada, seguida pelo sujeito ativo visando minar o equilíbrio emocional do sujeito passivo, por meio de atos, palavras, gestos e silêncios significativos que pretendam enfraquecer e diminuir sua autoestima ou causar outra forma de tensão ou desequilíbrio emocionais graves.

Segundo Ferreira (2004, p. 124) infelizmente o assédio moral é utilizado como ferramenta de "recrutamento" de trabalhadores com perfis desejáveis pelo mercado. Segundo ela, a tática empresarial consiste em submeter os trabalhadores a situações indignas e aviltantes e os que se resistem a elas passam a sofrer uma série de retaliações por parte da empresa, um verdadeiro terrorismo psicológico. Elas objetivam, então, livrar-se dos trabalhadores indesejados sem arcar com custos de dispensa, como as verbas trabalhistas decorrentes da demissão imotivada, obrigandoos a pedir demissão e a abrir mão de seus direitos.

Embora aparentemente pareça que a empresa está lucrando com essas práticas, é importante salientar que isso não ocorre na verdade. Como se verá adiante, não é apenas a vítima que sofre as consequências do fenômeno, já que empresa de um modo geral e também o assediador sofrerão as consequências desses atos.

\subsection{TIPOS DE ASSÉDIO LABORAL}

Quanto aos tipos, o assédio moral classifica-se com base na hierarquia existente entre agressor e agredido ou assediador e assediado e pode ser classificado em vertical descendente, vertical ascendente, horizontal e misto.

Hirigoyen (2005, p. 111), realizou uma pesquisa elencando os tipos de assédio existentes, em que contou com a participação de 186 pessoas, esta concluiu que em $58 \%$ dos casos, o assédio provém da hierarquia, sendo que em $29 \%$ dos casos, o assédio provém de diversas pessoas, incluindo chefia e colegas; em $12 \%$ dos casos, o assédio vem de colegas, enquanto em apenas $1 \%$ dos casos, o assédio é perpetrado por um subordinado.

Ainda, outro dado importante é com relação à ocorrência de assédio em determinados locais com maior frequência, como é o caso do setor terciário, no setor 


\section{Personalidade Acadêmica Homenageada:}

\section{Carlos Aurélio Mota de Souza (Universidade Ibirapuera - UNIB)}

de medicina social e do ensino, ou seja, nos locais em que as tarefas não estão definidas e nos quais em consequência é sempre possível culpar outro por alguma coisa. (HIRIGOYEN, 2005, p.122)

\subsubsection{Assédio Moral Vertical Descendente}

Também chamado de assédio estratégico, esse é o tipo de assédio mais comum nas empresas e ocorre durante a execução de um contrato de trabalho e iniciase de cima para baixo, ou seja, de um diretor ou gerente, por exemplo, para um empregado subordinado.

Tendo em vista a existência de subordinação da vítima, existe o receio do empregado em perder o seu emprego. Neste tipo de assédio é muito comum também, o trabalho em conjunto dos colegas juntamente com o superior hierárquico, que se unem contra a vítima objetivando desestruturá-la psicologicamente. (GUEDES, 2008, p. 39)

\subsubsection{Assédio Moral Vertical Ascendente}

O assédio moral vertical ascendente é o menos comum, mas também ocorre no ambiente de trabalho.

É o caso de um superior hierárquico vitimado pelos colegas subordinados a ele e é tão cruel e perverso quanto os demais tipos de assédio.

Um exemplo dado por Guedes (2008, p. 39) é o de uma jovem bacharela em direito que foi nomeada para ocupar cargo de diretora de secretaria numa Vara do interior. Devido a sua pouca idade e inexperiência, foi hostilizada e desprezada por grande parte dos funcionários. Porém, embora todo o sofrimento gerado pela situação, neste caso, sua determinação foi decisiva para que preservasse seu cargo e autoridade. 


\section{Personalidade Acadêmica Homenageada:}

\section{Carlos Aurélio Mota de Souza (Universidade Ibirapuera - UNIB)}

\subsubsection{Assédio Moral Horizontal}

Os colegas de trabalho também podem ser perpetradores de atitudes que configuram assédio moral. Geralmente tal modalidade ocorre devido à competitividade, preferência pessoal do chefe, inveja, xenofobia, preconceito racial, político ou religioso, etc. Esse assédio pode ocorrer de forma individual ou coletiva, sendo que, no último caso, parece que todos os funcionários resolvem colaborar com o perverso, piorando ainda mais o quadro.

\subsubsection{Assédio Moral Misto}

É muito comum que com o decorrer do tempo o assédio moral horizontal, devido à omissão da chefia ou superior hierárquico, torne-se também assédio moral vertical descendente, já que a vítima passa a ser perseguida por todos e não apenas pelos colegas.

Tal tipo de assédio é bastante prejudicial para a vítima já que esta fica desamparada no ambiente de trabalho, pois de um lado seus colegas são os agressores, e igualmente seus superiores hierárquicos também se voltam contra ele, restando um ambiente solitário e hostil.

\subsection{MÉTODOS DE ASSÉDIO UTILIZADOS PELO AGRESSOR}

São inúmeras as situações que caracterizam o terror psicológico no trabalho e por isso, faz-se necessário uma análise acerca dos diversos métodos utilizados pelo agressor para atingir a vítima.

Guedes (2008, p. 51) com base em seus estudos e também nos de Heinz Leymann e Marie-France Hirigoyen elenca alguns comportamentos que caracterizam o fenômeno.

A primeira delas é a recusa à comunicação, ou seja, a possibilidade de comunicação da vítima é limitada, eis que sempre é interrompida ou tratada aos berros. Seu trabalho é constantemente criticado com expressões grosseiras e com 


\title{
Personalidade Acadêmica Homenageada:
}

Carlos Aurélio Mota de Souza (Universidade Ibirapuera - UNIB)

ameaças verbais, por telefone ou escritas. A vítima é evitada pelos colegas, desprezada e não sabe para onde pedir socorro. (GUEDES, 2008, p. 51)

A segunda agressão é a desqualificação. Muito sutil e indireta, a desqualificação caracteriza-se com suspiros, dar de ombros, questionamento sobre sua competência profissional, silêncio geral e constrangedor quando a vítima emite alguma opinião e ridicularizada perante os colegas, levando-a a desestruturação e a agir agressivamente perante os demais.

\begin{abstract}
A outra forma de assédio moral é destruição da autoestima da vítima, com o objetivo de atingir sua intimidade e leva-la a desacreditar de si. Inicia com brincadeiras de mau gosto, insinuações, silêncio quando a vítima chega num grupo, humilhada, ridicularizada, recebendo até apelidos com o objetivo de minar sua autoestima. (GUEDES, 2008, p. 52).
\end{abstract}

A terceira forma de caracterizar o fenômeno é através do isolamento, que muitas vezes é a primeira atitude tomada pelo assediador para destruir sua vítima. Por meio do isolamento faz-se com que o indivíduo não tenha relações sociais com os demais colegas, já que é colocada em sala separada, almoça sozinha, não é convidada a participar de reuniões ou passam-lhe o horário errado para esta ser responsabilizada pelo atraso, etc. (GUEDES, 2008, p. 53)

O último método defendido pela autora é o constrangimento. Fixação de metas impossíveis de serem atingidas, obrigar a vítima ficar até tarde da noite trabalhando e ver seu trabalho menosprezado ou jogado no lixo, ter suas atividades fiscalizadas ao extremo inclusive com controle fisiológico, e até agressões físicas indiretas como esbarrões ou objetos lançados "sem querer" na vítima sempre com o intuito de humilhar e constrange-la. (GUEDES, 2008, p. 54)

Verifica-se, assim, uma infinidade de métodos utilizados pelo agressor para desestabilizar a vítima, fazendo com que esta sinta-se totalmente desamparada e acuada e, sem alternativas, solicite sua demissão ou seu afastamento devido a doenças psicológicas ou psicossomáticas decorrentes do fenômeno. 


\section{Personalidade Acadêmica Homenageada:}

Carlos Aurélio Mota de Souza (Universidade Ibirapuera - UNIB)

\section{CONSEQUÊNCIAS DO FENÔMENO NA RELAÇÃO DE TRABALHO}

\subsection{CONSEQUÊNCIAS PARA A VÍTIMA DO ASSÉDIO}

Conforme já demonstrado, são inúmeras as atitudes perpetradas pelos assediadores para atingir a vítima. Não raras vezes esta chega a tentar suicídio, tão grande é o abalo sofrido e a incapacidade de gerir essas situações dentro de si.

Leyman (2008, p. 49) grande estudioso do assunto, preconiza que o assédio moral é uma forma extrema de estresse social no ambiente laboral. Segundo ele, o tratamento clínico desses pacientes avançou quando descobriu que a desordem póstraumática por estresse (PTSD) era o diagnóstico psiquiátrico e psicologicamente correto para $95 \%$ dos pacientes tratados por ele como vítimas do terror no trabalho. Leymann demonstrou ainda que dos 64 diagnósticos efetuados, apontou um severo grau de PTSD compatível com um oriundo da guerra e da tortura nas prisões ou nos campos de concentração.

Quanto o assédio moral é recente e existe alguma possibilidade de reação ou esperança de solução da situação, os sintomas são similares ao do estresse, como cansaço, nervosismo, distúrbios do sono, dores na coluna e enxaquecas, etc. É o corpo se defendendo da agressão e se adaptando à situação. Já quando o estresse se origina de uma situação de assédio moral, há também o sentimento de impotência, humilhação e a ideia de anormalidade da situação. Nesta fase ainda há possibilidade de a pessoa se recuperar rapidamente se for afastada do agressor ou, ainda, se the pedirem desculpas pelos atos praticados, o que o levará a recuperar seu equilíbrio, diminuindo os riscos de sequelas. (HIRIGOYEN, 2005, p. 159)

Já se o fenômeno ocorre há mais tempo a pessoa vitimada poderá apresentar tristeza, apatia, complexo de culpa ou desinteresse com seus próprios valores. Hirigoyen apresentou dados do da Classificação internacional de doenças mentais que comprovou que $69 \%$ das respostas acusaram um estado depressivo severo que justificou o acompanhamento médico com sério risco de suicídio, contra $24 \%$ de respostas que levaram a um estado depressivo leve. (HIRIGOYEN, 2005, p. 160) 


\section{Personalidade Acadêmica Homenageada:}

\section{Carlos Aurélio Mota de Souza (Universidade Ibirapuera - UNIB)}

São incontáveis as consequências do assédio na vida e na saúde da vítima. O assédio moral pode provocar uma destruição da identidade e influenciar por muito tempo o temperamento da pessoa. Considerando que a identidade das pessoas se constroem progressivamente desde a infância, ela nunca está definitivamente formada. Quando se é vítima de uma agressão contra a qual não há meios de defesa, poderá ocorrer uma acentuação nos traços de personalidade anteriores ou até mesmo surgirem distúrbios psiquiátricos. É uma verdadeira alienação, já que a pessoa perde o próprio domínio de si mesma. (HIRIGOYEN, 2005, p. 175)

Como são incontáveis os prejuízos à saúde do trabalhador e, considerando que ele necessita do seu trabalho para sobreviver e garantir a subsistência de sua família, o que pode ser feito para livrar-se de tal situação e minimizar os efeitos do assédio em sua saúde?

Se já existe uma situação de assédio moral instaurada, o trabalhador vitimado, deverá munir-se de provas suficientes para comprovar a ocorrência do fenômeno do qual está sendo vítima. A própria Consolidação das Leis Trabalhistas traz, em seu artigo 483, "d", a possibilidade de resolução contratual por parte do empregado com relação ao empregador, através da rescisão indireta do contrato de trabalho.

Isso quer dizer que, assim como o empregador pode demitir o empregado por justa causa se ele incorrer em uma das atitudes previstas no artigo 482 da CLT, o empregado não precisa e não deve pedir demissão. Ele pode, por intermédio do Poder Judiciário, aplicar uma justa causa ao empregador se este praticar uma das atitudes previstas no artigo 483 da CLT, através da rescisão indireta do contrato de trabalho, a qual, só poderá ser aplicada mediante processo judicial após a comprovação em juízo do assédio ocorrido. Desta forma, configurada a hipótese, o trabalhador terá seu contrato de trabalho rescindido como se tivesse sido demitido sem justa causa, podendo receber o seguro-desemprego (se possuir os requisitos para tal) e sacar o FGTS, além da multa fundiária prevista para esta modalidade de demissão, além de outras verbas trabalhistas.

Em pesquisa de campo realizada, verificou-se que os efeitos ao trabalhador ofendido são desastrosos, pois além de conduzi-lo à demissão, ao desemprego e também à dificuldade de relacionar-se, causa sintomas psíquicos e físicos, que variam 


\section{Personalidade Acadêmica Homenageada:}

\section{Carlos Aurélio Mota de Souza (Universidade Ibirapuera - UNIB)}

um pouco entre as vítimas, dependendo do seu sexo. As mulheres, de maneira geral, são sujeitas a crises de choro, palpitações, tremores, tonturas e falta de apetite enquanto o homem tem sede de vingança, ideia de suicídio, falta de ar e uso de drogas. (BARROS, 2009, p. 935)

\subsection{CONSEQUÊNCIAS PARA O ASSEDIADOR}

Dada a ilicitude da atitude praticada pelo assediador, esta pode ser passível de punição pelo empregador. Como já dito, por ora não há tipificação penal contra a prática do assédio moral, porém, na esfera privada o assediador poderá sofrer as sanções cabíveis.

Para garantir as boas relações de trabalho e a ordem na organização, a empresa deve valer de seu poder disciplinar para punir o empregado que violar as regras legais e contratuais estabelecidas por este, aplicando contra o infrator a penalidade da rescisão do contrato de trabalho por justa causa, ou seja, sem efeito pecuniário para o empregador em razão da conduta ilícita perpetrada pelo empregado. ( ALKIMIN, 2008, p. 99)

Alkimin (2008, p. 101) ressalta ainda que o empregado poderá ser demitido por justa causa tanto por mau procedimento (artigo 482,b), como por ato lesivo da honra e boa fama, ou ofensas físicas, praticadas contra empregador, superior hierárquico ou qualquer pessoa (artigo 482, "j" e "k" da CLT).

Para Wagner Giglio, o mau procedimento é definido como "todo e qualquer ato faltoso grave, praticado pelo empregado, que torne impossível, ou sobremaneira onerosa, a manutenção do vínculo empregatício, e que não se enquadre na definição das demais justas causas." ( ALKIMIN, 2005, p. 101)

Portanto, é necessário que o agressor seja devidamente punido por seus comportamentos para que não perpetuem essas atitudes na instituição e faça cada vez mais vítimas, prejudicando todo o ambiente organizacional. 


\section{Personalidade Acadêmica Homenageada:}

\section{Carlos Aurélio Mota de Souza (Universidade Ibirapuera - UNIB)}

\subsection{CONSEQUÊNCIAS PARA O EMPREGADOR E PARA A ORGANIZAÇÃO}

Além disso, é inconteste que todo o sistema organizacional é afetado pela ocorrência do assédio moral, diminuindo a produtividade não apenas da vítima, mas de todos os envolvidos neste ciclo.

Importante salientar ainda que a livre iniciativa seja um dos princípios constitucionais fundamentais previstos na Constituição da República Federativa do Brasil, ela deve estar em consonância com os demais preceitos constitucionais. Assim, não pode o empregador alegar a livre iniciativa em face ao direito à dignidade do trabalhador. Ele deverá agir conforme as limitações legais respeitando os empregados e proporcionando a estes um equilibrado ambiente do trabalho como preconiza a lei. (MATHIES, 2018, p. 74)

Da mesma maneira, a ocorrência de assédio moral no ambiente de trabalho viola à ordem jurídica vigente, ocasionando consequências jurídicas e econômicas ao empregador, já que este é diretamente responsável pelos danos causados ao empregado, respondendo pecuniariamente pelos prejuízos materiais e morais ocasionados à vítima, inclusive quando os perpetradores são colegas de trabalho e não diretamente os chefes ou sócios da organização dada a responsabilidade objetiva atribuída ao empregador.

Além dos custos provenientes desses processos judiciais e das condenações deles provenientes, as consequências do assédio para 0 empregador poderão culminar numa maior rotatividade de mão-de-obra, além da diminuição da eficácia e da produtividade, não só das vítimas do assédio moral como também de colegas de trabalho afetados pelo clima psicossocial negativo típico nessas situações. (OLIVEIRA apud MATHIES 2018, p. 74) 


\section{Personalidade Acadêmica Homenageada:}

Carlos Aurélio Mota de Souza (Universidade Ibirapuera - UNIB)

\section{ASSÉDIO MORAL: PROVA, PREVENÇÃO E REPARAÇÃO DE DANOS}

\subsection{PROVA DO ASSÉDIO MORAL E DO DANO}

Sabe-se da prática forense a grande dificuldade enfrentada pelos operadores do direito para comprovar a ocorrência do assédio moral no ambiente do trabalho dada a hostilidade com que este ocorre.

Não raras vezes o assédio acontece apenas "entre quatro paredes" sem que outra pessoa além da vítima e do assediador tenham presenciado tais comportamentos.

No entanto, segundo Barros (2009, p.930) , algumas características são fundamentais para se configurar o dano: a intensidade da violência psicológica, o prolongamento no tempo em que as situações ocorreram, além da finalidade em ocasionar um dano psíquico, e que se produzam efetivamente danos psíquicos.

A prova do assédio moral no trabalho como já apontado é bastante difícil e incumbe à vítima. Assim, esta deverá apresentar indícios que levem a uma razoável suspeita, aparência ou até presunção da ocorrência do fenômeno alegado. Por outro lado, incumbirá ao demandado demonstrar que sua conduta foi razoável, ou seja, que não atentou contra qualquer direito fundamental. No caso do assédio, caso o julgador não realize a correta distribuição da carga probatória, as condenações por assédio moral não surtirão os efeitos necessários, banalizando o fenômeno, o que não deveria ocorrer dada a sua nocividade. (BARROS, 2009, p.940)

Desta forma, tendo em vista a dificuldade probatória, é fundamental que o trabalhador, ciente de que está sendo vítima do assédio moral, junte as provas necessárias à sua comprovação, podendo assim, amparar suas alegações junto ao judiciário para obter a devida reparação e resolução contratual.

Simm (2008, p. 156) entende que o mais adequado nesses casos é que nos casos de assédio moral vertical descendente e horizontal exija-se do trabalhador uma prova meramente indiciária, proporcionando ao julgador indícios que gerem uma razoável suspeita ou aparência dos fatos ou atos descritos, como a produção de um início de prova razoável dos fatos que possa resultar numa presunção ou suposição 


\section{Personalidade Acadêmica Homenageada:}

\section{Carlos Aurélio Mota de Souza (Universidade Ibirapuera - UNIB)}

de maltrato psicológico capaz de lesionar direitos fundamentais. Assim, "caso o autor se desincumbisse desse ônus, caberia então ao empregador (no caso de assédio descendente) o ônus de evidenciar que usa ação ou atitude ocorreu segundos critérios de objetividade, racionalidade e proporcionalidade e com base em fatores reais e concretos."

Ainda, segundo o mesmo autor, não significa impor prova negativa ao empregador em comprovar que não existiu lesão a direito fundamental, mas sim que seu ato teve motivação razoável e alheia a qualquer propósito de vulnerar direito fundamental do trabalhador, observando-se critérios de necessidade, da adequação e proporcionalidade como já anunciado. Mas no caso de assédio horizontal, a prova do empregador deverá se ater às providências tomadas com o fim de evitar ou cessar a conduta hostil do agressor. (SIMM, 2008, p. 156)

\subsection{A PREVENÇÃO DA OCORRÊNCIA DO FENÔMENO NAS EMPRESAS}

A melhor forma de combater o assédio moral no trabalho é a prevenção. Tanto empregados como empregadores devem estar preparados para se defenderem desse fenômeno antes que se torne mais um caso judicial.

Guedes (2008, p. 159) afirma ainda que paralelamente a isso, é importante que os trabalhadores se informem e tomem consciência da gravidade das consequências do assédio não apenas na saúde do indivíduo atingido, mas na higidez no ambiente de trabalho como um todo, entendendo que a violência sofrida a um colega hoje, poderá reverter-se contra si amanhã.

No âmbito do assédio moral, a compliance tem se mostrado uma ferramenta bastante eficaz na prevenção de inúmeras irregularidades perpetradas pelos trabalhadores, dentre elas a ocorrência do assédio moral. A verificação constante do clima organizacional, bem como a realização de pesquisas de satisfação internas, acompanhamento e controle de licenças para tratamento de saúde de empregados podem auxiliar a empresa na eliminação dos riscos decorrentes do referido fator de afastamento. 


\section{Personalidade Acadêmica Homenageada:}

\section{Carlos Aurélio Mota de Souza (Universidade Ibirapuera - UNIB)}

Após verificar a ocorrência do assédio moral e localizar o agressor ou agressores, é necessário que as correções necessárias sejam realizadas para coibir a continuidade do comportamento abusivo. O imediato desligamento por justa causa do agressor ou a aplicação de uma sanção disciplinar ao empregado imediatamente após a falta ocorrida, são de suma importância para coibir atitudes faltosas por parte dos funcionários de maneira geral. Por outro lado, a omissão da empresa somente alavancaria e estimularia tais situações. (MATHIES, 2018, p. 161)

\subsection{REPARAÇÃO DOS DANOS MORAIS}

O assédio moral ainda não possui tipificação no Código Penal apesar da conscientização de que a caracterização de assédio é uma situação gravíssima e que necessita uma maior atenção por parte dos legisladores. A nova Lei 13.467 de 13 de julho de 2017 passou a disciplinar questões relativas ao dano extrapatrimonial (dano moral no sentido amplo), como é o caso do dano moral decorrente do assédio moral.

O novo artigo 223-C da CLT estabelece a tutela jurídica da honra, imagem, intimidade, liberdade de ação, autoestima, sexualidade, saúde, lazer e integridade física, no âmbito da relação de trabalho, reafirmando o direito fundamental insculpido na Carta Magna, acerca da dignidade da pessoa humana. (BRASIL, 2018)

No mesmo artigo em seu item " $G$ ", o legislador fixa que na apreciação do pedido o juiz deverá considerar a natureza do bem jurídico tutelado, a intensidade do sofrimento e da humilhação sofridos, a possibilidade de superação física ou psicológica, os reflexos pessoais e sociais da ação ou da omissão, a extensão e a duração dos efeitos da ofensa, as condições em que ocorreu a ofensa ou o prejuízo moral, o grau de dolo ou culpa, a ocorrência de retratação espontânea, o esforço efetivo para minimizar a ofensa, o perdão tácito ou expresso, a situação social e econômica das partes envolvidas e, ainda, o grau de publicidade da ofensa.(BRASIL, 2018)

Ainda, após a caracterização e averiguação dos critérios para definir a gravidade da ofensa, o julgador deverá atentar para o valor das indenizações que pode ser de até três vezes o último salário contratual do ofendido no caso de ofensa leve, 


\section{Personalidade Acadêmica Homenageada:}

\section{Carlos Aurélio Mota de Souza (Universidade Ibirapuera - UNIB)}

até cinquenta vezes o último salário contratual do ofendido, conforme determinado pelo $\S 1^{\circ}$ do mesmo diploma legal supra. (BRASIL, 2018)

\section{CONCLUSÃO}

De todo o estudo realizado, procurou-se analisar o assédio moral e seus aspectos gerais, os efeitos do fenômeno na relação laboral, bem como as formas de prevenir e reparar os danos gerados ao trabalhador.

Verificou-se que as consequências oriundas do assédio são altamente destrutivas, inclusive podendo ensejar à vítima uma grave depressão ou tentativas de suicídio, além de refletir na produtividade do trabalhador ofendido e até mesmo na organização como um todo.

É necessário, todavia, que estas empresas não incentivem a competição a qualquer custo, pois esta é sem dúvida, a porta de entrada para a ocorrência do fenômeno. A empresa deve ter objetivos e regras de conduta previamente estabelecidos, a fim de coibir qualquer tendência à ocorrência do assédio.

Verificou-se, entretanto, que não basta apenas o trabalhador ter os seus direitos assegurados pela Constituição, mas sim deve-se ter a garantia da aplicação da tutela jurisdicional. É nessário que este mal seja combatido, com o emprego de medidas judiciais preventivas e interruptivas do assédio, com o objetivo de combater o comportamento do agressor e também fornecer os elementos necessários para que o próprio trabalhador tenha ferramentas adequadas para sua defesa, a fim de fazer cessar ou, até mesmo, impedir a ocorrência dos ataques.

\section{REFERÊNCIAS}

ALKIMIN, Maria Aparecida. Assédio Moral na Relação de Trabalho. Curitiba. Juruá, 2008.

BARROS, Alice Monteiro de. Curso de Direito do Trabalho. 5 ed. São Paulo. Ltr, 2009. 
Personalidade Acadêmica Homenageada:

Carlos Aurélio Mota de Souza (Universidade Ibirapuera - UNIB)

BRASIL. Consolidação das Leis Trabalhistas 2017. Disponível em: http://www.planalto.gov.br/ccivil_03/Decreto-Lei/Del5452.htm em 28 de agosto de 2018.

DELGADO, Mauricio Godinho. Curso de direito do trabalho. 17. Ed. São Paulo: LTr, 2018.

FERREIRA, Hádassa Dolores Bonilha. Assédio moral nas relações de trabalho. Campinas: Russel , 2004.

GIGLIO, Wagner. Apud ALKIMIN, Maria Aparecida. Assédio Moral na Relação de Trabalho. Curitiba: Juruá, 2008.

GOMES, Dinaura Godinho Pimentel. Direito do trabalho e dignidade da pessoa humana, no contexto da globalização econômica: problemas e perspectivas. São Paulo: LTr, 2005.

GUEDES, Márcia Novaes. Terror Psicológico no Trabalho. São Paulo: LTr, 2008.

HIRIGOYEN, Marie France. Mal-estar no trabalho: redefinindo o assédio moral. Tradução de Rejane Janowitzer. Rio de Janeiro; Bertrand Brasil, 2005.

LEYMANN; GUSTAFSSON, apud GUEDES, Márcia Novaes. Terror Psicológico no Trabalho. São Paulo: LTr.

MATHIES, Anaruez. Assédio Moral e compliance nas relações de emprego: dos danos e dos custos e instrumentos de prevenção de acordo com a reforma trabalhista. Curitiba: Juruá, 2018.

OLIVEIRA, Paulo Eduardo Vieira de. Apud MATHIES. Assédio Moral e compliance nas relação de emprego: dos danos e dos custos e instrumentos de prevenção de acordo com a reforma trabalhista. Curitiba: Juruá, 2018.

SIMM, Zeno. Acosso psíquico no ambiente de trabalho: manifestações, efeitos, prevenção e reparação. São Paulo; Ltr, 2008. 